\title{
ACESSIBILDIADE DIGITAL: DIREITO FUNDAMENTAL PARA AS PESSOAS
} COM DEFICIÊNCIA

\author{
DIGITAL ACCESSIBILITY: FUNDAMENTAL RIGHT TO PERSONS WITH \\ DISABILITIES
}

\author{
Flávia Piva Almeida Leite ${ }^{1}$ \\ Samantha Ribeiro Meyer-Pflug ${ }^{2}$
}

\section{RESUMO}

Trata-se de analisar no presente artigo o direito de acessibilidade digital das pessoas com deficiência. Nesse sentido, examina-se com acuidade o conceito de acessibilidade digital em todos os seus aspectos. De igual modo estuda-se, com profundidade, sua acepção como direito fundamental das pessoas com deficiência e como medida de relevância para a inclusão dessas pessoas e para a plena aplicabilidade do direito ao acesso à informação constitucionalmente previsto. O método utilizado é o dedutivo e a pesquisa bibliográfica.

Palavras-chave: Acessibilidade digital, inclusão de pessoas com deficiência, Direito à informação

\section{ABSTRACT}

It is to examine in this article the right to digital accessibility for people with disabilities. In this sense, acuteness with it examines the concept of digital accessibility in all its aspects. Similarly it is studied with depth, its meaning as a fundamental right of people with disabilities and how important measure for the inclusion of these people and the full applicability of the right of access to constitutionally provided information. The method used is the deductive and literature

Keywords: Digital accessibility, inclusion of people with disabilities, Right to information

\footnotetext{
${ }^{1}$ Doutora pela Pontifícia Universidade Católica - PUC, São Paulo, (Brasil). Professora da Graduação e Mestrado em Direito da Faculdades Metropolitanas Unidas - FMU. Advogada. E-mail: flaviaaleite3@ hotmail.com

${ }^{2}$ Doutora em Direito pela Pontifícia Universidade Católica - PUC, São Paulo, (Brasil). Professora da Graduação e Mestrado em Direito da Universidade Nove de Julho - UNINOVE. Advogada.
} 


\section{INTRODUÇÃO}

A preocupação da sociedade para com as pessoas que ostentam alguma forma deficiência não vem de hoje. Mas, sem dúvida, não deixa de ser relativamente recente a melhor conscientização social e jurídica do problema que enfrentam essas pessoas.

A imagem obsessiva do corpo humano belo e perfeito tornou-se evidente desde os tempos mais antigos. As pessoas com deficiência, por não se inserirem nessa imagem idealizada, foram muitas vezes brutalmente eliminadas e excluídas da sociedade. $\mathrm{Na}$ Antiguidade e Idade Média, essa concepção foi tão profunda que, não só influenciou a sociedade, mas também a construção de suas cidades. Na antiga Roma, os romanos partiram do método Vitruviano para planejarem suas cidades. Essa corrente, que utiliza a escala humana ideal como medida de referência no projeto arquitetônico, é seguida como norma até hoje. Daí, ambientes construídos e projetados sem considerar a diversidade dessas pessoas.

Somente após a ocorrência das duas grandes Guerras Mundiais, a sociedade em geral começa a esboçar uma sensibilização e uma conscientização positiva, principalmente em relação às pessoas com deficiência, ocasionando uma mudança de postura.

Com essa atitude, a questão da inclusão das minorias étnicas, culturais, de gênero toma relevo e passa a ser reconhecida em documentos nacionais e internacionais. Esse novo paradigma social traz como princípios a celebração da valorização da diversidade humana, solidariedade humanitária, igual importância a esses grupos vulneráveis e cidadania com qualidade de vida.

Dentro dessa perspectiva, a Constituição Federal de 1988 inaugura uma nova fisionomia ao Estado brasileiro, vez que não somente o consagrou democrático, mas também, ressaltou o seu caráter essencialmente social, ao fundá-lo em valores como a dignidade humana e a cidadania, que repercutem sobre o ordenamento como um todo e ao mesmo tempo serve de norte para toda e qualquer iniciativa privada e pública.

Ademais, o Brasil, na busca pela implementação dos direitos das pessoas com deficiência, e no nosso trabalho, o direito à acessibilidade, não só ao meio físico, mas também aos meios de comunicação e novas tecnologias, assina no dia 30 de março de 2007, a Convenção sobre os Direitos das Pessoas com Deficiência e seu Protocolo Facultativo, promulgados pela Organização das Nações Unidas. Sua eficácia foi reconhecida em âmbito nacional com a edição do Decreto-legislativo 18608. 
Para concretizar os direitos das pessoas com deficiência, é aprovada aqui no Brasil a Lei ${ }^{\circ}$ 13.146, de 02 de julho de 2015 que Institui a Lei Brasileira de Inclusão da Pessoa com Deficiência (Estatuto da Pessoa com Deficiência), que em seu Título III, assegura o direito à acessibilidade aos meios de informação e comunicação, inclusive de sistemas e tecnologias da informação e comunicação, e de outros serviços.

Porém, para que haja uma sociedade verdadeiramente democrática, isto é, aquela que concretize o direito de todos e não apenas da maioria, temos que concretizar com eficiência a tal almejada inclusão social. Não é uma tarefa fácil entender o seu real significado, pois um de seus princípios, segundo preceitua SASSAKI (1999, p.50) é a rejeição zero, também conhecida como exclusão zero. Isto quer dizer que, ou se adere totalmente aos seus princípios, ou não se fala em inclusão.

\section{A INCLUSÃO DA PESSOA COM DEFICIÊNCIA NA CONSTITUIÇÃO FEDERAL DE 1988}

As dificuldades passadas pelas pessoas com deficiência pelos muitos séculos da História do Homem jamais deixaram de existir. Essa verdade sempre foi válida em todos os quadrantes da Terra, em qualquer época, sendo válida também para todos os períodos da História do Brasil.

$\mathrm{Na}$ verdade, a pessoa com deficiência no Brasil foi considerada por vários séculos dentro da categoria mais ampla dos miseráveis, talvez o mais pobre dos pobres. Quando essas pessoas nasciam de famílias mais abastadas, certamente, passavam o resto de seus dias escondidos em suas grandes mansões, fazendas ou em casas de campo de suas famílias, ficando totalmente excluídos do convívio social, permanecendo como um peso para suas respectivas famílias. (SILVA, 2009).

A partir do século XX, a sociedade em geral passa a esboçar uma sensibilização e uma conscientização positiva em relação às pessoas com deficiência. Pode-se dizer que essa alteração se deu por vários fatores: uma filosofia social mais voltada para a valorização do homem, do engajamento de muitos setores da sociedade movidas pelo bem-estar comum, em consequiência dos evidentes progressos das ciências e suas aplicações práticas, em todos os 
campos, mas, especialmente, pelas ações destruidoras ocasionados pelas Grandes Guerras Mundiais. ${ }^{3}$

Quando do final da Segunda Guerra Mundial, o problema dos soldados vítimas de deficiências causadas pela guerra atrai a atenção, não só da sociedade, mas também da Organização das Nações Unidas, que juntamente com outras organizações de caráter internacionais ${ }^{4}$ (Fundo de Emergência das Nações Unidades para as Crianças - UNICEF, a Organização Internacional do Trabalho - OIT, a Organização Mundial de Saúde- OMS, a Organização das Nações Unidas para Refugiados e a Organização das Nações Unidas para Educação, Ciência e Cultura - UNESCO), criam grandes programas assistenciais com ênfase especial para dar soluções aos inúmeros e sérios problemas sociais causados pelos elevados contingentes de população vítimas das atividades da guerra. O problema da deficiência ocasionado pelos males da guerra era tão significativo que demandou a concentração de esforços em programas de reabilitação dessas pessoas.

Começa a haver uma conscientização no sentido de compreender que as pessoas com deficiência necessitavam não só dos cuidados que as instituições especiais pudessem lhes prover, mas também de atenção pessoal, carinho, de relacionamento familiar, enfim, de um ambiente que possibilitasse alguma participação na vida comunitária, como qualquer outra pessoa.

\footnotetext{
${ }^{3}$ Nesse mesmo sentido, esclarece Luiz, que "um importante divisor de águas para o estudo da proteção das pessoas portadoras de deficiência foi a ocorrência das duas grandes guerras mundiais, que fez aumentar, desgraçadamente, o número de pessoas portadoras de deficiência de locomoção e de audição" (ARAUJO, Luiz Alberto David A proteção constitucional das pessoas portadoras de deficiência. $2^{\mathrm{a}}$. ed. Brasília: CORDE, 1997. p. 15).

${ }^{4}$ Segundo anota Otto Marques da Silva, em sua obra Epopeia Ignorada, as responsabilidades das Organizações Internacionais foram sendo gradativamente definidas, estando envolvidas no desenvolvimento de programas de assistência técnica ou de financiamento de projetos localizados nos países em desenvolvimento. Esses projetos cobriam os mais variados aspectos da educação e da reabilitação de pessoas com deficiência, por meio de especialistas em campo, bolsas de estudos para profissionais e publicações consideradas relevantes. A Unidade de Reabilitação de Pessoas com Deficiência na ONU, com sede em Nova York, ficou encarregada ficou encarregada de variados aspectos de Planejamento, Administração, Legislação, Aspectos Sociais, Aspectos Psicológicos e Próteses. A Organização Internacional do Trabalho, sediada em Genebra, cobria todos os aspectos de vida de trabalho das pessoas com deficiência. A Organização das Nações Unidas para Refugiados e a Organização das Nações Unidas para Educação, Ciência e Cultura - UNESCO, com sede em Paris, tem como competência técnica desenvolvimento atividades de assistência técnica em educação especial para pessoas com deficiência. A OMS, com sede em Genebra, tem a responsabilidade de promover a saúde, em sentido amplo, às pessoas com deficiência. E o Fundo de Emergência das Nações Unidades para as Crianças - UNICEF, sediado em Nova York nas instalações da ONU, somente prestava assistência de natureza financeira a projetos que tinham a aprovação técnica da relevante Agência das Nações Unidas, ou seja, da Organização Mundial de Saúde, da UNESCO, da Organização das Nações Unidas para Refugiados e da própria Unidade de Reabilitação de Pessoas Deficientes do Bureau de Assuntos Sociais da ONU. Cf. Epopeia ignorada. Século XX. Responsabilidades das Organizações Internacionais. Parte I. Capítulo Décimo segundo. CD Epopéia Ignorada, Cotia: Editora Faster, 2009.
} 
Com esse tipo de raciocínio dominante, a Assembléia Geral da ONU manteve muitos esforços para dar cobertura aos problemas sociais que enfrentavam as pessoas com deficiências, tanto que a partir dos anos 50, juntamente com o Conselho Econômico e Social das Nações Unidas, passou a aprovar resoluções sobre prevenção e reabilitação.

No ano de 1955, a Organização Mundial do Trabalho lança a recomendação $n^{\circ} 99$ sobre a Reabilitação de Pessoas Portadoras de Deficiência. No ano de 1971, a Assembléia Geral da ONU aprova a resolução ${ }^{\circ}$ 28/56, Declaração dos Direitos do Retardo Mental, que afirma que as pessoas com deficiência mental têm os mesmos direitos dos demais seres humanos. Em 1975, a Assembléia Geral da ONU aprova a resolução n 34/47 relacionada à Declaração dos Direitos das Pessoas com Deficiência ${ }^{5}$, afirmando que às pessoas com deficiência têm o direito inerente ao respeito à sua dignidade, aos mesmos direitos civis, políticos, econômicos, sociais e culturais que as demais pessoas, aliada ao "direito de terem tratamentos médicos, psicológico e funcional, à reabilitação, aos serviços de colocação e a outros serviços que lhes possibilitarão desenvolver suas capacidades e habilidades ao máximo e acelerarão o processo de sua integração ou reintegração social,"” que implica antes de tudo, no direito de desfrutar de uma vida decente, normal e plena.

No ano de 1981 foi proclamado pela Assembléia Geral das Nações Unidas, pela Resolução $n^{\circ}$ 31/123, o Ano Internacional das Pessoas com Deficiência com o tema "Participação e Igualdade", com ênfase na prevenção, reabilitação e equiparação de oportunidades. O propósito dessa declaração universalmente conhecida era dar condições para a implementação das Resoluções anteriores, através da conscientização do mundo todo quanto à problemática das pessoas com deficiências. (SILVA, 2009).

Neste contexto, surge o processo de integração social com intuito de derrubar a prática da exclusão social a que foram submetidas às pessoas com deficiência por vários séculos, começando a inserí-las nos sistemas sociais gerais como a educação, o trabalho, a família e o lazer.

Essa nova prática pouco exigia da sociedade em termos de modificação de atitudes, de objetos, de práticas sociais e de espaços físicos, afinal, a pessoa com deficiência é que teria que se transformar, se modificar e se adequar às exigências da sociedade. Esperava-se que,

\footnotetext{
5 A Declaração definiu o termo "pessoas deficientes" como qualquer pessoa incapaz de assegurar por si mesma, total ou parcialmente, as necessidades de uma vida individual ou social normal, em decorrência de uma deficiência, congênita ou não, em suas capacidades físicas ou mentais.
} 
após a reabilitação, a pessoa com deficiência reabilitada estava apta a assumir o seu lugar na sociedade.

Era um processo de mão única, em que a sociedade ficava de braços cruzados, aceitava receber as pessoas com deficiência, mas essas tinham que se amoldar aos serviços especiais, ficando separadas em classe especial, acompanhando os procedimentos tradicionais, contornando os obstáculos existentes no meio físico, lidando com a discriminação da sociedade e desempenhando com autonomia, mas não necessariamente independência os papeis de aluno, trabalhador, pai, consumidor etc.. (SASSAKI, 1999. p. 35).

Esse modelo mostrou que essa prática social era insuficiente para acabar com a discriminação, como também pouco eficiente para propiciar a verdadeira participação das pessoas com deficiência em igualdade de oportunidades no âmbito social.

A Assembléia Geral da ONU, nos anos subseqüentes, caminhou gradativamente para uma desejável conscientização quanto à garantia não apenas dos direitos, mas também dos meios para que as pessoas com deficiência tivessem condições de acesso à sociedade de forma plena e em igualdade de condições.

No ano de 1993, a Assembléia Geral da ONU adotou o documento "Normas sobre a Equiparação de Oportunidades para as Pessoas com deficiência" (Resolução 44/70). Em todas as definições trazidas por essa norma está implícito o princípio da igualdade de direitos. No seu parágrafo 24 definiu o termo equiparação de oportunidades como o processo através do qual os diversos sistemas da sociedade e do ambiente, tais como serviços, atividades, informações e documentação, são tornados disponíveis para todos, particularmente para pessoas com deficiência.

Essas recomendações se destacaram das demais resoluções da ONU na área da deficiência e tiveram uma importância significativa na história normativa de seus direitos, tanto que serviram de parâmetro para práticas de políticas e leis de muitos países. No Brasil, o Decreto $\mathrm{n}^{\circ} 3.29899$, que regulamentou a Lei $\mathrm{n}^{\circ} 7.853 / 89$ definiu a Política de Integração Nacional da Pessoa Portadora de Deficiência com base nessas normas adotadas pela ONU.

$\mathrm{Na}$ tentativa de avançar no processo de construção de uma sociedade que respeite a diversidade, tem-se início o movimento de inclusão social, cujo objetivo é a construção de uma sociedade para todas as pessoas; não cabe somente as pessoas com deficiência se integrarem à sociedade, mas, é preciso que a sociedade também se transforme para acolher todos os seus cidadãos. 
Conforme ensina SASSAKI (1999, p.17), a inclusão se inspira sob novos princípios, quais sejam: celebração de diferenças, direito de pertencer, valorização da diversidade humana, solidariedade humanitária, igual importância das minorias e cidadania com qualidade de vida. A inclusão social pode ser conceituada como um processo pelo qual a sociedade se adapta para poder incluir as pessoas com deficiência e, simultaneamente, estas se preparam para assumir seus papeis na sociedade (SASSAKI, 1999. p.41). Conseqüentemente, a inclusão social é um processo de mão dupla, ou seja, tanto a pessoa com deficiência como a sociedade precisam se modificar.

É um processo que demandará a construção de um novo tipo de sociedade através de transformações, pequenas e grandes, na mentalidade de todas as pessoas, e especificamente, após o advento da Convenção dos Direitos da Pessoa com Deficiência nos ambientes físicos das cidades, conforme adiante será abordado.

No Brasil, a Constituição Federal de 1988 não destoou dessa evolução que já se vinha operando no mundo todo. Consagrou em diversas passagens à proteção da pessoa com deficiência, no sentido de assegurar à sua inclusão social. São reforçadas as regras que asseguram a dignidade da pessoa humana (artigo $\left.1^{\circ}, \mathrm{III}\right)$, cidadania (artigo $\left.1^{\circ}, \mathrm{I}\right)$ e a igualdade $\left(\operatorname{artigo} 5^{\circ}\right.$ ), seguida por diversas leis protetivas que visam reconhecer a inclusão dessas pessoas na sociedade. Assim, apesar das inúmeras disposições constitucionais e legais que asseguram a inclusão das pessoas com deficiência, muitas dificuldades e barreiras ainda existem, impossibilitando, mesmo agora, a plena acessibilidade, e consequentemente a utilização dos espaços de forma plena, segura e com autonomia e, em nosso estudo, a acessibilidade às comunicações e tecnologias.

\section{2- CONCEITO DE ACESSIBILIDADE}

O nosso ordenamento jurídico, preocupado com o número de pessoas com deficiência, à época $10 \%$ da população brasileira, tratou de reconhecer o processo de exclusão que vivia esse grupo, entendendo ser necessário garantir formas de proteção especial.

A mais caracterizadora dessas proteções é a acessibilidade às pessoas com deficiência, assegurada, não de forma genérica, mas, expressamente no artigo 227, parágrafo segundo, que determina que os edifícios de uso público e os veículos de transporte coletivo serão acessíveis. Por essa norma, todos os imóveis de uso público e transporte coletivo deveriam ser adaptados a partir de 05 de outubro de 1988. O constituinte foi mais insistente, 
ao determinar no artigo 244 que as adaptações deveriam atingir os bens existentes quando da promulgação da Constituição, deixando mais uma vez materializada essa garantia.

A Lei n. 10.098/2000, em seu art. $2^{\circ}$, I, definiu a acessibilidade como sendo a possibilidade e condição de alcance para utilização, com segurança e autonomia, dos espaços, mobiliários e equipamentos urbanos, das edificações, dos transportes e dos sistemas e meios de comunicação por pessoa com deficiência ou mobilidade reduzida. Conforme veremos logo a seguir, tal dispositivo foi revogado pela Lei Brasileira de Inclusão da Pessoa com Deficiência em seu art. 112, I, ampliando referida definição. A atual NBR138 9050/2004, que veio substituir a NBR 9050/85, ambas da Associação Brasileira de Normas Técnicas, ampliou o termo definindo a acessibilidade como a "possibilidade e condição de alcance, percepção e entendimento para a utilização com segurança e autonomia de edificações, espaço, mobiliário, equipamento urbano e elementos".

Acessível é definido como "espaço, edificação, mobiliário, equipamento urbano ou elemento que possa ser alcançado, acionado, utilizado e vivenciado por qualquer pessoa, inclusive aquelas com mobilidade reduzida", implicando tanto a acessibilidade física como a de comunicação. Cabe esclarecer que as normas técnicas, embora sejam de uso voluntá- rio, passam a ter força de lei quando mencionadas explicitamente no corpo legislativo. É o que ocorreu com as normas técnicas de acessibilidade da Associação Brasileira de Normas Técnicas, que passaram a integrar a Lei n. 10.098/2000, o Decreto n. 5.296/2004 e a Lei n. $13.146 / 2015$.

Para dar eficácia a esses dispositivos constitucionais, o legislador ordinário elaborou diversas leis protetivas às pessoas com deficiência6, sendo a mais específica a Lei $\mathrm{n}^{\circ}$ 10.098, de 19 de dezembro de 2000. Que em seu artigo 2, inciso I, define a acessibilidade como sendo a possibilidade e condição de alcance para utilização com segurança e autonomia, dos espaços, mobiliários e equipamentos urbanos, das edificações, dos transportes e dos sistemas e meios de comunicação por pessoa com deficiência ou mobilidade reduzida. O termo acessibilidade indica a condição de livre acesso, de possibilidade. Falar em acessibilidade em

\footnotetext{
${ }^{6}$ Lei $n^{\circ} 7.853 / 89$, que dispõe sobre o apoio às pessoas portadoras de deficiência, sua integração social, sobre a CORDE, institui a tutela jurisdicional de interesses coletivos ou difusos dessas pessoas, disciplina a atuação do Ministério Público, define crimes, e dá outras providências. A acessibilidade foi novamente tratada pela lei ${ }^{\circ}$ $10.048 / 00$ que assegura tratamento prioritário às pessoas com deficiência, idosos, às gestantes, às lactantes e às pessoas acompanhadas por crianças de colo.

Lei n ${ }^{\circ}$ 10.436/2002 que dispõe sobre a Língua Brasileira de Sinais (Libras), para garantir acesso à comunicação e informação dos surdos na educação, trabalho e demais serviços públicos;

A Lei $\mathrm{n}^{\mathrm{o}} 11.126 / 2005$, que assegura à pessoa com deficiência visual usuária de cão guia o direito de ingressar e permanecer com o animal nos veículos e nos estabelecimentos públicos e privados de uso coletivo.
} 
termos gerais, segundo José Antonio Lanchotti é "compreender a possibilidade de acesso, da aproximação, da utilização, do manuseio de qualquer objeto, local, ou condição e, tudo isso, deve ser oferecido com facilidade, não exigindo do usuário um esforço excessivo". (LANCHOTI, 2005, p. 28).

O Decreto n. 5.29604 levou o Poder Executivo - Presidente da Republica, a alterar o conceito de acessibilidade definido no artigo 2, inciso I da Lei 10.09800, visto anteriormente. No artigo 8, inciso I, desse Decreto, a acessibilidade foi considerada como "condição para utilização com segurança e autonomia, total ou assistida, dos espaços...”. (grifo nosso). Todavia, GUIMARÃES (2010) assevera que a "acessibilidade assistida" equivale à falta de acessibilidade, pois esse termo é contrário "às noções de independência, autodeterminação, espontaneidade e autonomia que são básicas para o uso ambiental bem sucedido por todas as pessoas". Mais adiante, o mesmo autor diz que a acessibilidade assistida se constitui como barreiras arquitetônicas para as pessoas com deficiência que se vêem impossibilitadas de utilizarem dos recursos ambientais previstos para sua acessibilidade. (grifo nosso).

No mesmo sentido, ao comentar a alteração do conceito legal introduzido pelo Decreto 5.29694, RIBEIRO (2007, p. 35) diz que a noção de autonomia é elemento de extrema importância para a garantia da liberdade, igualdade e dignidade das pessoas com deficiência. Afirma ainda que, dentro de uma concepção sistemática que caracteriza nosso ordenamento jurídico, qualquer texto normativo não deve ser interpretado em pedaços e, sim, no seu todo, e para a interpretação do direito à autonomia devem ser levadas em consideração, dentre outros diplomas legais, as diretrizes estabelecidas na Lei $n^{\circ} 7.853 / 89$. Na aplicação e interpretação dessa lei, deve-se observar prioritariamente, os valores básicos da igualdade de tratamento e oportunidade, da justiça social, do respeito à dignidade da pessoa, do bem-estar (arts. $1^{\circ}$ e $2^{\circ}$ ), o que está reforçado pelas disposições do Decreto $n^{\circ} 3.29899$, que definem como princípios da Política Nacional para Integração da Pessoa com Deficiência, em consonância com o Programa Nacional de Direitos Humanos, dentre outros, o desenvolvimento de ação conjunta do Estado e da sociedade civil para a inclusão (art. $5^{\circ}$ ).

Embora as palavras autonomia e independência sejam sinônimas segundo os dicionários convencionais, tais palavras têm significados diferentes dentro do enfoque trazido pelo movimento inclusivista.

“Autonomia”, segundo SASSAKI (1999, pp. 76-77), diz respeito ao domínio do ambiente físico e social, sem tirar a dignidade da pessoa que a está exercendo. Tem como 
denominador comum o controle maior ou menor da pessoa portadora de deficiência sobre o ambiente em que se locomove.

Mais adiante, o mesmo autor esclarece que "independência" se refere à capacidade da pessoa portadora de deficiência em decidir se precisa depender mais ou menos de outrem, certamente, também, relacionada à sua própria identidade, à compreensão exata de sua dimensão, com o mundo que a cerca e autodeterminação com prontidão e decisão daquilo que ela pode desenvolver em termos de realização, que lhe facilitem a independência e a autonomia. Sempre atentas sobre a intensidade maior ou menor, conforme o seu estado físico, mas mais atentos ainda para o que, nesse estado físico dependente, ela possa conseguir ou eliminar.

Será que podemos falar em liberdade e principalmente, em igualdade, se um usuário da internet não consegue acessar a web diariamente, em busca de acesso a informação, entretenimento, trabalho, educação, comercio, entre outras atividades devido a falta de tecnologia ou ferramentas que possibilitem o acesso amplo e irrestrito à informação digital?

As pessoas que necessitam do auxílio de outras para alcançar seus objetivos não vivenciam a essência do conceito da acessibilidade universal em nenhum momento. (GUIMARÃES, 2010). Só ha que se falar em inclusão das pessoas com deficiência se houver acessibilidade com autonomia e independência. $\mathrm{O}$ objetivo da acessibilidade é proporcionar à todas as pessoas, e, principalmente às pessoas com deficiência, um ganho de autonomia e mobilidade, para que possam usufruir dos espaços com mais segurança, confiança e comodidade. (PRADO, 2006. p. 11).

Com o advento da Convenção sobre os Direitos das Pessoas com Deficiência e seu Protocolo Facultativo passam a ser o primeiro Tratado Internacional a ingressar na nossa ordem jurídica interna com status de equivalência constitucional, por ter sido aprovado nos exatos termos da regra imposta pelo $\S 3^{\circ}$ do artigo $5^{\circ}$ da Constituição Federal. A finalidade dessa Convenção não foi apenas a de instituir novos direitos humanos e liberdades fundamentais para as pessoas com deficiência, mas em garantir que essas pessoas possam vir a desfrutá-los em igualdade de condições com todos os demais direitos, sem discriminação. E para que isso ocorra, reforça a ideia de que as barreiras, e em nosso estudo, as barreiras físicas, impedirão a possibilidade dessas pessoas de usufruírem de seus direitos em condições de igualdade.

Cabe esclarecer que a principal contribuição desta Convenção é a positivação da mudança de paradigma da visão da deficiência no mundo, que passa do modelo médico, no 
qual a deficiência é tratada como um problema de saúde, para o modelo social dos direitos humanos, no qual a deficiência é resultante de uma equação que tem duas variáveis, quais sejam as limitações funcionais do corpo humano e, no caso do nosso trabalho, das barreiras tecnológicas ou nas comunicações.

Todos os direitos garantidos pela Convenção sobre os Direitos das Pessoas com Deficiência, a partir desse novo paradigma positivado, têm o intuito de emancipar todas as pessoas com deficiência, oportunizando o pleno e efetivo exercício e gozo de seus direitos e garantias fundamentais. Tanto que, em seu preâmbulo, registra que deficiência é um conceito em evolução e que ela resulta da interação entre pessoas com deficiência e as barreiras ambientais que impedem sua plena e efetiva participação na sociedade, em igualdade de oportunidades com as demais pessoas. Portanto, ao ter reconhecido que a deficiência é um conceito em evolução, constatou-se que essas pessoas têm capacidades e que, se elas tiverem informações e comunicações acessíveis, terão oportunidades que nunca antes puderam vivenciar.

Para que a pessoa com deficiência exerça de forma efetiva o direito à acessibilidade, a Convenção determinou também em seu artigo $9^{\circ}$, que os Estados estarão obrigados a tomar medidas apropriadas para assegurar a sua efetivação, em igualdade de oportunidades com as demais pessoas, ao meio físico, ao transporte, à informação e comunicação, bem como a outros serviços e instalações abertos ao público ou de uso público, tanto na zona urbana como na rural. ${ }^{7}$ Como bem delineada desse dispositivo, a pessoa com deficiência, para ter garantida

${ }^{7}$ 1. A fim de possibilitar às pessoas com deficiência viver de forma independente e participar plenamente de todos os aspectos da vida, os Estados Partes tomarão as medidas apropriadas para assegurar às pessoas com deficiência o acesso, em igualdade de oportunidades com as demais pessoas, ao meio físico, ao transporte, à informação e comunicação, inclusive aos sistemas e tecnologias da informação e comunicação, bem como a outros serviços e instalações abertos ao público ou de uso público, tanto na zona urbana como na rural. Essas medidas, que incluirão a identificação e a eliminação de obstáculos e barreiras à acessibilidade, serão aplicadas, entre outros, a:

a) Edifícios, rodovias, meios de transporte e outras instalações internas e externas, inclusive escolas, residências, instalações médicas e local de trabalho;

b) Informações, comunicações e outros serviços, inclusive serviços eletrônicos e serviços de emergência. 2.Os Estados Partes também tomarão medidas apropriadas para:

a) Desenvolver, promulgar e monitorar a implementação de normas e diretrizes mínimas para a acessibilidade das instalações e dos serviços abertos ao público ou de uso público;

b) Assegurar que as entidades privadas que oferecem instalações e serviços abertos ao público ou de uso público levem em consideração todos os aspectos relativos à acessibilidade para pessoas com deficiência; 
a autonomia e qualidade devida, necessita de recursos que aumentem, mantenham ou melhorem suas capacidades funcionais, tais recursos podem também vir através de serviços e/ou produtos denominados tecnologias assistidas ou ajudas técnicas. Claro que essa acessibilidade melhorará a acessibilidade arquitetônica, urbanística, de transporte, e no nosso estudo, a de comunicação e digital dessas pessoas. Dentro desse contexto, o Comitê de Ajudas Técnicas (CAT) junto ao Ministério da Justiça, aprovou em 2007, o seguinte conceito:

Tecnologia Assistiva é uma área do conhecimento, de característica interdisciplinar, que engloba produtos, recursos, metodologias, estratégias, práticas e serviços que objetivam promover a funcionalidade, relacionada à atividade e participação de pessoas com deficiência, incapacidades ou mobilidade reduzida, visando sua autonomia, independência, qualidade de vida e inclusão social. ${ }^{8}$

Para BERSH (2013) o objetivo maior da tecnologia assistiva ou TA é proporcionar à pessoa com deficiência maior independência, qualidade de vida e inclusão social, através da ampliação de sua comunicação, mobilidade, controle de seu ambiente, habilidades de seu aprendizado e trabalho. Assim, a Convenção, ao reconhecer o modelo social como o mais novo paradigma para conceituar as pessoas com deficiência, embasa também a consolidação da acessibilidade tanto como princípio, quanto como um direito. E como princípio-direito obriga os Estados à sua implementação como garantia fundamental, extremamente relevante para a concretização dos direitos humanos das pessoas com deficiência. ${ }^{9}$

c) Proporcionar, a todos os atores envolvidos, formação em relação às questões de acessibilidade com as quais as pessoas com deficiência se confrontam;

d) Dotar os edifícios e outras instalações abertas ao público ou de uso público de sinalização em braille e em formatos de fácil leitura e compreensão;

e) Oferecer formas de assistência humana ou animal e serviços de mediadores, incluindo guias, ledores e intérpretes profissionais da língua de sinais, para facilitar o acesso aos edifícios e outras instalações abertas ao público ou de uso público;

f) Promover outras formas apropriadas de assistência e apoio a pessoas com deficiência, a fim de assegurar a essas pessoas o acesso a informações;

g) Promover o acesso de pessoas com deficiência a novos sistemas e tecnologias da informação e comunicação, inclusive à Internet;

h) Promover, desde a fase inicial, a concepção, o desenvolvimento, a produção e a disseminação de sistemas e tecnologias de informação e comunicação, a fim de que esses sistemas e tecnologias se tornem acessíveis a custo mínimo.

${ }^{8}$ Disponível em : httpp://www.mj.gov.br/sedh/ct/dorde/dpdh/corde/comite at.asp

${ }^{9}$ Especificamente o disposto no preâmbulo da Convenção, alínea “v”. Bem como o artigo $3^{\circ}$, “f”, que define a acessibilidade como um dos princípios gerais a reger a Convenção. E no artigo $9^{\circ}$, trata da acessibilidade como um direito, inclusive obrigando os Estados a tomarem medidas apropriadas para assegurá-lo. 
Considerando a acessibilidade como condição de livre acesso, de aproximação, de utilização, do manuseio de qualquer objeto, local, ou condição, é seu objetivo proporcionar a todas as pessoas, e, principalmente às pessoas com deficiência, um ganho de autonomia e mobilidade, para que possam usufruir dos espaços com mais segurança, confiança e comodidade. E para que isso ocorra, a Convenção determina que todos os ambientes, como princípio e regra ao mesmo tempo, eliminem as barreiras existentes, especialmente as que forem criadas pelo próprio ser humano e que novos espaços sejam desenhados livres de barreiras, para não obstaculizar o pleno gozo e exercício dos direitos das pessoas com deficiência.

Portanto, acessibilidade na web é a possibilidade e a condição de alcance, percepção, entendimento e interação para a utilização, a participação e a contribuição, em igualdade de oportunidades, com segurança e autonomia, em sítios e serviços disponíveis na web, por qualquer indivíduo, independentemente de sua capacidade motora, visual, auditiva, intelectual, cultural ou social, a qualquer momento, em qualquer local e em qualquer ambiente físico ou computacional e a partir de qualquer dispositivo de acesso. Por ser um processo de transformação do ambiente e desenvolver-se a partir do reconhecimento social de que a deficiência é resultante do desajuste entre as características físicas das pessoas e as condições onde elas atuam, a acessibilidade passa a ser retomada como um tema de grande importância para o planejamento urbano.

A acessibilidade se constituiu num direito instrumental, afinal, sem acesso aos equipamentos urbanos, às escolas, aos postos de saúde, aos transportes públicos, as informações e comunicações as pessoas com deficiência não podem exercer, plenamente, a sua cidadania. Não há o exercício da inclusão social sem acessibilidade.

A presença da acessibilidade no meio urbano, bem como nas edificações, nos transportes, na informação e comunicação, inclusive aos sistemas e tecnologias da informação e comunicação e nas suas mútuas interações é uma exigência constitucional. Surge, atualmente, de acordo com a Convenção sobre o Direito das Pessoas com Deficiência, como um direito forte, o que impacta na concepção contemporânea dos direitos humanos e impõe sua releitura, sob essa nova perspectiva.

A acessibilidade dentro desse novo contexto constitucional surge como um direito fundamental. No entanto, ainda há necessidade de leis que implementem tal direito. A efetivação ainda não se concretizou, o que se verifica facilmente pela falta de acesso à internet, pela existência de barreiras na informação e comunicação que impedem que as 
pessoas com deficiência possam usufruir de forma plena e autônoma dos sistemas e tecnologias da informação e comunicação.

Indo ao encontro desse direito fundamental ao acesso, é aprovada a Lei $\mathrm{n}^{\circ} 13.146$, de 6 de julho de 2015 que institui a Lei Brasileira de Inclusão da Pessoa com Deficiência (Estatuto da Pessoa com Deficiência). Que em seu Título III, assegura a acessibilidade, dispondo em seu artigo 55 que: "a concepção e a implantação de projetos que tratem do meio físico, de transporte, de informação e comunicação, inclusive de sistemas e tecnologias da informação e comunicação, e de outros serviços, equipamentos e instalações abertos ao público, de uso público ou privado de uso coletivo, tanto na zona urbana como na rural, devem atender aos princípios do desenho universal, tendo como referência as normas de acessibilidade."

Percebemos que leis não faltam para assegurar às pessoas com deficiência o direito fundamental ao acesso, todavia ainda não concretizado. Mas poderá se efetivar. E esse é o objetivo pretendido referida Lei Brasileira de Inclusão da Pessoa com Deficiência - Lei $n^{\circ}$ 13.146, de 02 de julho de 2015 que Institui a Lei Brasileira de Inclusão da Pessoa com Deficiência (Estatuto da Pessoa com Deficiência).

\section{3- ACESSIBILIDADE NA LEI BRASILEIRA DE INCLUSÃO DA PESSOA COM DEFICIÊNCIA}

A Agenda de Túnis da Cúpula Mundial da Sociedade da Informação, realizada em 2005, atribuiu à UNESCO um papel de liderança na implementação de ações para promover o acesso à informação e ao conhecimento. Nesse contexto, um resultado esperado é a inclusão digital e social de pessoas com deficiência, por meio da ampliação do acesso à informação em formato digital para a promoção de uma cidadania mais informada, educada e ativa. (DEFOURNY, 2007).

Já que vivemos cada vez mais interligados pela internet, muitas vezes buscando trabalho, entretenimento, educação, comércio etc, a grande maioria dos sites não levam em consideração uma parcela importante dessa população. Segundo dados do IBGE (Instituto de Geografia e Estatística), através do Censo Demográfico realizado em 2010, verificamos que a população atual de pessoas com deficiências é de 45.623.910 cidadãos, o que correspondente a 23,9\% da população brasileira atual e, de acordo com o mesmo órgão, cerca de 25 milhões de deficientes, apenas cerca de 10 mil ou mais têm acesso ao computador e à internet, o que é 
um número bem reduzido, mas que, se forem criadas e oportunizadas melhores condições de acesso, esse número poderá aumentar consideravelmente.

A Lei $\mathrm{n}^{\circ} 13.146$ de 2015 é bastante didática e enfática ao dispor sobre a acessibilidade digital dos deficientes físicos. Ela estabelece que é obrigatória a acessibilidade nos sítios da internet mantidos por empresas com sede ou representação comercial no País ou por órgãos de governo, para uso da pessoa com deficiência, garantindo-lhe acesso às informações disponíveis, conforme as melhores práticas e diretrizes de acessibilidade adotadas internacionalmente. Importante registrar que os sítios devem conter símbolo de acessibilidade em destaque. De igual modo, os Telecentros comunitários que receberem recursos públicos federais para seu custeio ou sua instalação e "lan houses" devem possuir equipamentos e instalações acessíveis. Eles também devem garantir, no mínimo, dez por cento de seus computadores com recursos de acessibilidade para pessoa com deficiência visual, sendo assegurado pelo menos um equipamento, quando o resultado percentual for inferior a um. Fica estabelecido também que as empresas prestadoras de serviços de telecomunicações deverão garantir pleno acesso à pessoa com deficiência, conforme regulamentação específica. Incumbe a referida Lei ao poder público incentivar a oferta de aparelhos de telefonia fixa e móvel celular com acessibilidade que, entre outras tecnologias assistivas, possuam possibilidade de indicação e de ampliação sonoras de todas as operações e funções disponíveis. Os serviços de radiodifusão de sons e imagens devem permitir o uso dos seguintes recursos, entre outros: a) subtitulação por meio de legenda oculta; b) janela com intérprete da Libras; c) audiodescrição. Cabe ao poder público também adotar mecanismos de incentivo à produção, à edição, à difusão, à distribuição e à comercialização de livros em formatos acessíveis, inclusive em publicações da administração pública ou financiadas com recursos públicos, com vistas a garantir à pessoa com deficiência o direito de acesso à leitura, à informação e à comunicação. Nos editais de compras de livros, inclusive para o abastecimento ou a atualização de acervos de bibliotecas em todos os níveis e modalidades de educação e de bibliotecas públicas, o poder público deverá adotar cláusulas de impedimento à participação de editoras que não ofertem sua produção também em formatos acessíveis. Para os efeitos da lei em comento consideram-se formatos acessíveis os arquivos digitais que possam ser reconhecidos e acessados por softwares leitores de telas ou outras tecnologias assistivas que vierem a substituí-los, permitindo leitura com voz sintetizada, ampliação de caracteres, diferentes contrastes e impressão em Braille. O poder público deve estimular e apoiar a adaptação e a produção de artigos científicos em formato acessível, inclusive em 
Libras. Deve assegurar o Poder público a disponibilidade de informações corretas e claras sobre os diferentes produtos e serviços ofertados, por quaisquer meios de comunicação empregados, inclusive em ambiente virtual, contendo a especificação correta de quantidade, qualidade, características, composição e preço, bem como sobre os eventuais riscos à saúde e à segurança do consumidor com deficiência, em caso de sua utilização. Os canais de comercialização virtual e os anúncios publicitários veiculados na imprensa escrita, na internet, no rádio, na televisão e nos demais veículos de comunicação abertos ou por assinatura devem disponibilizar, conforme a compatibilidade do meio, os recursos de acessibilidade de que trata a Lei n. 13.146, a expensas do fornecedor do produto ou do serviço. Os fornecedores devem disponibilizar, mediante solicitação, exemplares de bulas, prospectos, textos ou qualquer outro tipo de material de divulgação em formato acessível. No que se refere às instituições promotoras de congressos, seminários, oficinas e demais eventos de natureza científicocultural devem oferecer à pessoa com deficiência, no mínimo, os recursos de tecnologia assistiva. Os programas, as linhas de pesquisa e os projetos a serem desenvolvidos com o apoio de agências de financiamento e de órgãos e entidades integrantes da administração pública que atuem no auxílio à pesquisa devem contemplar temas voltados à tecnologia assistiva. Caberá ao poder público, diretamente ou em parceria com organizações da sociedade civil, promover a capacitação de tradutores e intérpretes da Libras, de guias intérpretes e de profissionais habilitados em Braille, audiodescrição, estenotipia e legendagem. A Lei também é expressa ao garantir à pessoa com deficiência acesso a produtos, recursos, estratégias, práticas, processos, métodos e serviços de tecnologia assistiva que maximizem sua autonomia, mobilidade pessoal e qualidade de vida. O poder público desenvolverá plano específico de medidas, a ser renovado em cada período de quatro anos, com a finalidade de: a) facilitar o acesso a crédito especializado, inclusive com oferta de linhas de crédito subsidiadas, específicas para aquisição de tecnologia assistiva; b) agilizar, simplificar e priorizar procedimentos de importação de tecnologia assistiva, especialmente as questões atinentes a procedimentos alfandegários e sanitários; c) criar mecanismos de fomento à pesquisa e à produção nacional de tecnologia assistiva, inclusive por meio de concessão de linhas de crédito subsidiado e de parcerias com institutos de pesquisa oficiais; d) eliminar ou reduzir a tributação da cadeia produtiva e de importação de tecnologia assistiva; e) facilitar e agilizar o processo de inclusão de novos recursos de tecnologia assistiva no rol de produtos distribuídos no âmbito do SUS e por outros órgãos governamentais. 
Mas como mencionamos anteriormente, é necessário que haja tecnologia assistiva adequada e adaptada as suas necessidades especiais, principalmente os deficientes visuais e auditivos, caso contrário, ficarão gravemente limitados quanto a quantidade e a qualidade de informações que podem acessar a internet, o que impediria que eles utilizassem de forma plena e autônoma as potencialidades deste meio de comunicação. Dentre as categorias de tecnologia assistiva, BERSH (2013) aponta recursos de acessibilidade ao computador como conjunto de hardware e software especialmente idealizado para tornar o computador acessível a pessoas com privações sensoriais (visuais e auditivas), intelectuais e motoras. Nestes dispositivos inclui os de entrada (mouses, teclados e acionadores diferenciados) e de saída (sons, imagens, informações táteis).

Traz como exemplos desses dispositivos de entrada os teclados modificados, os teclados virtuais com varredura, mouses especiais e acionadores diversos, software de reconhecimento de voz, dispositivos apontadores que valorizam movimento de cabeça, movimento de olhos, ondas cerebrais (pensamento), órteses e ponteiras para digitação, entre outros. E como exemplos de dispositivos de saídas softwares leitores de tela, software para ajustes de cores e tamanhos das informações (efeito lupa), os softwares leitores de texto impresso (OCR), impressoras braile e linha braile, impressão em relevo, entre outros.

Alguns órgãos internacionais coordenam e elaboração a padronização das regras de acessibilidade. O World Wide Web Consortium (W3C) é um consórcio internacional em que organizações filiadas, uma equipe em tempo integral e o público trabalham juntos para desenvolver padrões para a web. O W3C já publicou mais de cem padrões, como HTML, CSS, RDF, SVG e muitos outros. Todos os padrões desenvolvidos pelo W3C são gratuitos e abertos, visando garantir a evolução da web e o crescimento de interfaces interoperáveis. O W3C Brasil iniciou suas atividades em 2008 por iniciativa do Comitê Gestor da Internet no Brasil (CGI.br) e do Núcleo de Informação e Coordenação do Ponto BR (NIC.br). O W3C Brasil acompanha as discussões de alcance mundial sobre o desenvolvimento dos padrões, com uma atenção especial a temas como: Open Web Platform, dados abertos e acessibilidade na web além de contar com o Grupo de Trabalho de Acessibilidade na Web do W3C Brasil (GT Acessibilidade na Web), criado em março de 2012, o grupo se reúne periodicamente para planejar ações a serem realizadas no Brasil. Em 2013, o grupo contava com mais de sessenta pessoas, entre elas representantes do governo federal, estadual e municipal de diversos estados, membros de instituições para pessoas com deficiência, acadêmicos e representantes da sociedade civil. 
Assim, para que a acessibilidade na web seja alcançada, a W3C-WAI identifica sete componentes:

1) Conteúdo é a informação contida numa página ou aplicação web, incluindo:

- a informação natural, tal como texto, imagem e áudio;

- o código ou marcação, que define a estrutura, a forma de apresentação, etc.

2) Navegadores são os tocadores de conteúdo multimídia e outros agentes do usuário.

3) Tecnologia assistiva é aquela usada por pessoas com deficiência e mobilidade

reduzida, como é o caso dos programas leitores de tela, dos ampliadores de tela, dos teclados alternativos, entre outros.

4) O conhecimento do usuário, sua experiência e, em alguns casos, suas estratégias adaptativas para a utilização da web.

5) Desenvolvedores, designers, codificadores, autores, entre outros, incluindo pessoas com deficiência que são desenvolvedores e usuários que contribuem com conteúdo.

6) Ferramentas de autoria (authoring tools): softwares usados para criar sítios web.

7) Ferramentas de avaliação: avaliadores de acessibilidade, validadores de HTML, validadores de CSS, entre outros. ${ }^{10}$

Esses componentes são essenciais e básicos para que os desenvolvedores de páginas possibilitem o acesso amplo e irrestrito à informação digital para as pessoas com deficiência, atendendo os requisitos estabelecido na Lei n. 13.146. No entanto, como visto, incumbe precipuamente, ao Poder Público incentivar e criar políticas públicas que possibilitem essa acessibilidade digital da pessoa com deficiência e desse modo garantir que eles possam exercer em sua plenitude sua cidadania. A acessibilidade digital é importante para o exercício da cidadania e para a garantia do direito fundamental ao acesso à informação e a consolidação da democracia.

Dentro desse contexto, constatamos que o direito fundamental ao acesso à pessoa com deficiência, não só ao meio físico, ao transporte, mas, notadamente na informação e comunicação está amplamente assegurado em nosso ordenamento jurídico.

\section{CONCLUSÃO}

É notório que a Humanidade sempre conviveu com a existência de pessoas com deficiência, e assim, a sua sobrevivência em todo mundo e em todas as épocas nunca deixou de ser uma luta, muitas vezes, totalmente ignorada pela sociedade e pelos governos como um todo.

${ }^{10}$ Cartilha de Acessibilidade na Web do W3C Brasil - Fascículo I - Introdução, p. 24 
Avançando no processo de construção de uma sociedade que respeite a diversidade, aprova-se com força de norma constitucional, a Convenção sobre os Direitos das Pessoas com Deficiência e seu Protocolo Facultativo cuja finalidade dessa Convenção não foi apenas a de instituir novos direitos humanos e liberdades fundamentais para as pessoas com deficiência, mas em garantir que essas pessoas possam vir a desfrutá-los em igualdade de condições com todos os demais direitos, sem discriminação. Indo ao encontro desse direito fundamental ao acesso, é aprovada a Lei $\mathrm{n}^{\circ}$ 13.146, de 6 de julho de 2015 que institui a Lei Brasileira de Inclusão da Pessoa com Deficiência (Estatuto da Pessoa com Deficiência). E para que isso ocorra, reforça a ideia de que as inúmeras barreiras, principalmente as de comunicação e tecnológicas impedirão a possibilidade dessas pessoas de usufruírem de seus direitos, notadamente da internet em condições de igualdade.

Portanto, a principal contribuição desta Convenção é a positivação da mudança de paradigma da visão da deficiência no mundo, que passa do modelo médico, no qual a deficiência é tratada como um problema de saúde, para o modelo social dos direitos humanos, no qual a deficiência é resultante de uma equação que tem duas variáveis, quais sejam as limitações funcionais do corpo humano e as diversas barreiras impostas pelo ambiente ao individuo e, em nosso estudo, as barreiras impostas na comunicação e tecnologias.

O direito à acessibilidade é, portanto, uma exigência constitucional que surge, atualmente, como um direito fundamental, notadamente para a pessoa com deficiência ou mobilidade reduzida possa desfrutar das mesmas oportunidades, a saber: educação, trabalho, habitação, lazer, cultura e as novas tecnologias da informação e comunicação. Esse direito fundamental à pessoa com deficiência foi amplamente assegurado em nosso ordenamento jurídico. Todavia, para que essas pessoas possam realizar de modo pleno e irrestrito esse direito fundamental e compartilhar os aspectos positivos das novas tecnologias, sobretudo no campo das comunicações, é essencial que lhes assegure a capacidade de utilizar da internet, onde as facilidade, a rapidez e a supressão de barreiras geográficas tornam possível o acesso aos mais diversos canais ponteciadores de conhecimento, mas também de convívio e lazer.

Constatamos que não faltam em nosso ordenamento jurídico leis que assegurem o direito ao acesso. Todavia, somente a normatividade desses direitos não é o bastante para garantir a implementação de ações para efetivar a acessibilidade de modo real e palpável às pessoas com deficiência, notadamente para acessar o mundo virtual da internet. A informação 
está na internet, mas ainda não está acessível para todos. Acessibilidade é um processo em construção!

\section{REFERÊNCIAS BIBLIOGRÁFICAS}

ALMEIDA PRADO, Adriana Romeiro de. Acessibilidade na gestão da cidade. In: ARAUJO, Luiz Alberto David. (Coord.). Defesa dos direitos das pessoas portadoras de deficiência. São Paulo: Editora Revista dos Tribunais, 2006.

BARTALOTTI, Celina Camargo. Inclusão social das pessoas com deficiência: utopia ou realidade?. São Paulo: Paulus, 2006. p. 14.

BERSCH, Rita. Introdução à tecnologia assistiva. Disponível em: http://www.assistiva.com.br/Introducao_Tecnologia_Assistiva.pdf Acesso em 04 outubro de 2015

COSTA SILVA, Waldir Macieira da. O direito fundamental à acessibilidade ao usuário com impedimentos físico-motores, perceptivos, sensoriais, intelectuais e mentais. In: LEITE, George Salomão; LEMOS, Ronaldo (coord.). Marco civil da internet. São Paulo: Editora Atlas, 2014.

DEFOURNY, Vincent. Apresentação da obra: Inclusão digital e social de pessoas com deficiência: textos de referência para monitores de telecentros. - Brasília: UNESCO, 2007.

GUIMARAES, Marcelo Pinto. Desenho universal é design universal: conceito ainda a ser seguido pelas normas técnicas 9050 e pelo Decreto-lei da Acessibilidade. Disponível em: Portal Vitruvius, htpp//www.vitruvius.com.br/arquitetos/arq096/arq096_03.asp Acessado em 10 de agosto de 2015

LANCHOTI, José Antonio. Critérios de desempenho da mobilidade no espaço urbano construído como avaliadores da cidade acessível: o caso de Ribeirão Preto. Tese de doutorado apresentada à Faculdade de Arquitetura e Urbanismo de São Paulo em Arquitetura, São Paulo, 2005. 
FILHO, Gildo Magalhães dos Santos. Comitê brasileiro de acessibilidade - CB 40. In: Município acessível ao cidadão. São Paulo, Fundação Prefeito Faria Lima - CEPAM, 2001.

RIBEIRO, Lauro Luiz Gomes. $O$ direito à igualdade, à dignidade da pessoa com deficiência e à autonomia. In: GUGEL, Maria Aparecida; COSTA FILHO, Waldir Macieira; RIBEIRO, Lauro Luiz Gomes (orgs.) Deficiência no Brasil - uma abordagem integral dos direitos das pessoas com deficiência. Florianópolis: Obra Jurídica, 2007.

SASSAKI, Romeu Kazumi. Inclusão - construindo uma sociedade para todos. $3^{\mathrm{a}}$ edição. Rio de Janeiro: Editora WVA, 1999. p. 50

SENNETT, Richard. A carne e a pedra. Tradução Marco Aarão Reis. Rio de Janeiro: BestBolso, 2008. pp., 44-45

SILVA, Otto Marques. Declarações de direitos e sua importância. Parte I. Capítulo Décimo Terceiro. CD Epopeia Ignorada, Cotia: Editora Faster, 2009.

STRECK, Lenio Luiz. Apontamentos hermenêuticos e o marco civil da internet. In: LEITE, Salomão George; LEMOS, Ronaldo. Marco civil da internet. São Paulo: Atlas, 2014. Verdade e consenso. $5^{\text {a }}$ ed. São Paulo: Saraiva, 2014. 